\title{
CONFIGURATION OF THE REFERENCE STATIONS AS THE ELEMENT OF NATIONAL REFERENCE FRAME RELIABILITY
}

\author{
Karolina SZAFRANEK *, Janusz BOGUSZ and Mariusz FIGURSKI
}

Kaliskiego St. 2, 00-908 Warsaw, Poland, Centre of Applied Geomatics, Military University of Technology

*Corresponding author's e-mail: kszafranek@wat.edu.pl

\section{ARTICLE INFO}

Article history:

Received 19 February 2013

Accepted 11 June 2013

Available online 26 November 2013

Keywords:

GNSS

Reference frame

ASG-EUPOS

Reference stations

\begin{abstract}
According to the newest Polish regulations multifunctional system of precise positioning ASGEUPOS serves as the fundamental network and constitutes reference frame as well. The permanent GNSS observations gathered within the network are processed and analysed by the Centre of Applied Geomatics of Military University of Technology, which is one of the EPN Local Analysis Centres. IGS and EUREF recommendations are included. Weekly solutions are being stacked and, as the result, cumulative solution (coordinates expressed at the specified epoch and velocities of all stations) by using the CATREF software and minimal constraints approach is determined. Its reliability increases with the number of reference (sometimes described as fiducial) stations. According to the EUREF guidelines, reference stations have to belong to the EPN A class, but their geographical layout leaves much to be desired. The authors made several numerous tests using different configuration of reference stations to transfer ETRF2000 frame into Poland area, and to choose the best strategy of ASG-EUPOS alignment to the EPN. Eight different variants of ASG-EUPOS processing were investigated and each time the different set of coordinates was obtained. The differences reached several centimetres. The spatial distribution of the results on the area of Poland was shown and the optimum solution was pointed out. Furthermore, the analysis on the Helmert transformation parameters from individual TRF to the reference network were performed. These parameters do not have any geophysical interpretation, but provide very useful information about solution's consistency and compliance.
\end{abstract}

\section{INTRODUCTION}

The GNSS (Global Navigation Satellite System) technique plays a vital role in the realization of ITRS (International Terrestrial References System). The IGS network (International GNSS Service, Dow et al., 2009) consists of over 400 permanent stations located around the globe, which increases the density of ITRF (International Terrestrial Reference Frame) network enabling the interconnection of other techniques (Altamimi and Collilieux, 2009). Subsequent distributions of the ITRF base on four techniques: GNSS, SLR (Satellite Laser Ranging), VLBI (Very Long Baseline Interferometry) and DORIS (Doppler Orbitography and Radiopositioning Integrated by Satellite).

Nowadays, with accuracies of position determination approaching for single millimetres, a consideration of growing number of factors that may affect the reliability of the determined coordinates seems to be important. GNSS technique, despite the obvious advantages, has some limitations associated with the problem of antennas calibration (Rebischung et al., 2012), discontinuities of coordinates caused by the replacement of equipment and artefacts of GPS resulting in aliased periodic signals in the coordinate time series (Penna and Stewart, 2003). The reliability of position determination using satellite navigation systems is also greatly affected by seasonal ionosphere changes (Shagimuratov et al., 2002).
One of such problems is the reference station selection to determine the coordinates of the analysed network of permanent GNSS stations in the chosen reference frame. Impact of the choice of stations on establishing a global network was described in (Wöppelmann et al., 2008), proving that the best results are obtained by using a large number of stations distributed globally. This eliminates the problems of individual stations. The test results of the influence of the number and location of reference stations and the number of parameters used to impose the minimal constraints on coordinates of regional solutions were shown in (Legrand and Bruyninx, 2009; Legrand et al., 2011). Using global reference stations, i.e. those which are distributed across the globe, does not deform regional network, while even a single station's malfunction (which reveals a significant difference between a priori values and the coordinates from the processing) can result in systematic errors throughout the network, especially if the station is located away from the barycentre of the network. Similar studies have been done to determine the impact of the regional references frame (reference station selection) and GNSS network layout on determined velocities (Legrand et al., 2010), where it has been shown that the reliability of the processing results increases with the number of stations and their geographical extent. Determined velocities have two main applications: they transfer coordinates of the 
reference frame to a given epoch and allow geodynamic interpretation. For ASG-EUPOS network, both issues are analysed by the Centre of Applied Geomatics of Military University of Technology, which is one of the EPN Local Analysis Centres (Araszkiewicz et al., 2011).

In accordance with the recommendations of the EUREF (Bruyninx et al., 2013), reference stations for the alignment of national network to the EPN (Bruyninx, 2004) must belong to the class A of the last ITRS/ETRS89 solution and have collected observations for the period coinciding with the measurements made for given study. Those stations, where the hardware have been replaced since the publication of last solution cannot be used as reference due to lack of coordinates for the observation scope after such modification.

To ensure a reliable alignment, data from minimum 5 EPN stations distributed around the processed network and all potentially contained within should be used. Stations with noisy time series and significant periodic disturbances should be excluded.

In case of the Polish ASG-EUPOS network the problem lies in the insufficient number of EPN class A stations located on the eastern side of the country and the relatively short period of class A station observation not covering the whole analysed interval. Several class A stations has a significant dispersion of the solutions and strong seasonal disturbances. From the north, Poland borders the Baltic Sea, which is also associated with a smaller number of stations that can be used as reference ones. To select the optimal alignment strategy of ASG-EUPOS to EPN and to assess its impact on the reliability of the ASG-EUPOS solutions, the authors performed a number of tests and calculations using different reference stations configurations transferring ETRF2000 on the Polish territory. The impact of the location of these stations on obtained coordinates has also been analysed.

\section{METHODOLOGY}

GNSS observations were collected by the ASG-EUPOS since February 2008, and therefore includes GPS weeks 1468-1600 (24 February 2008 - 11 September 2010). This range was determined by the interval covered by the solution EPN_A_ITRF2005_C1600 from 23 October 2010, used $^{-}$as a reference frame. Observations have been processed in the Bernese 5.0 software (Dach et al., 2007) according to the strategy used in the EPN described previously in (Kenyeres et al., 2009; Figurski et al., 2010). The result of the processing consisted of weekly solutions (coordinates with the full variance-covariance matrix in SINEX format (Solution Independent Exchange Format)). The analysis included data from several EPN stations located on the territory of Poland and beyond its borders to choose the optimal strategy of alignment.

The second stage consisted in accumulation of weekly solutions by means of CATREF software
(Altamimi et al., 2004). Designated solution (coordinates given at the specified epoch and velocities of all stations) is expressed in the reference frame implemented by given reference stations. Reference frame is transferred by introducing a minimum number of constraints (Altamimi, 2003).

The method of minimal constraints applied to align regional solutions to global (or local to regional) maintains the geometry of the network and does not deform it. This approach introduces only conditions for the abolition of the singularity of the normal equations matrix. It does not reduce the accuracy of the reference frame and is based on alignment of network to reference frame using 7-parameter Helmert transformation, taking into account changes of the parameters over time (Boucher and Altamimi, 2011).

In the first variant all EPN class A stations located on Polish territory and its surroundings (and included in the joint analysis of the data in the Bernese 5.0) were used as reference (Fig. 1a). Due to the fact that for a certain time since publication of a new global frame ITRF2008 (Altamimi et al., 2011) corresponding ETRF2000 system has not been published (solution basing on IGS08 was published in October 2012), stations belonging to the IGS network have been used as reference stations - variant No. 2 (Fig. 1b).

This variant is an example of reference stations of a similar geographic extent as variant No. 1, but with a much smaller number of stations. Coordinates and velocities of these stations are published in the consecutive ITRS realizations.

In variant No. 3 only class A EPN stations located on Polish territory were used as stations transferring reference frame (Fig. 2a). It seems to be obvious that the stations concentrated on a smaller area will have negative impact on the reliability of solutions, but this option has been introduced for tests to estimate the level of the geographical reference extent impact on the determined coordinates. In variant No. 4 (Figure 2b) all EPN class A stations with stable solutions time series were used. Such variant is the closest to the recommendations of EUREF therefore later was used as a reference solution to assess the quality of the solutions in the other variants.

Variants 5-8 consisted of reference stations only from specific direction, successively the southern (Fig. 3a), the western (Fig. 3b), the northern (Fig. 3c) and the eastern (Fig. 3d) stations were used. Such alignment should not be used, calculations were merely of test character and were made to see how the geographical distribution of reference stations affects the results. This is especially important in the case of a relatively small number of eastern stations that can be used to align the Polish network. For this reason, variant No. 5 is based on the south-western stations, and this type of "directional" alignment may result in poorer alignment of ASG-EUPOS to the EPN. Calculations using all variants were performed in the 

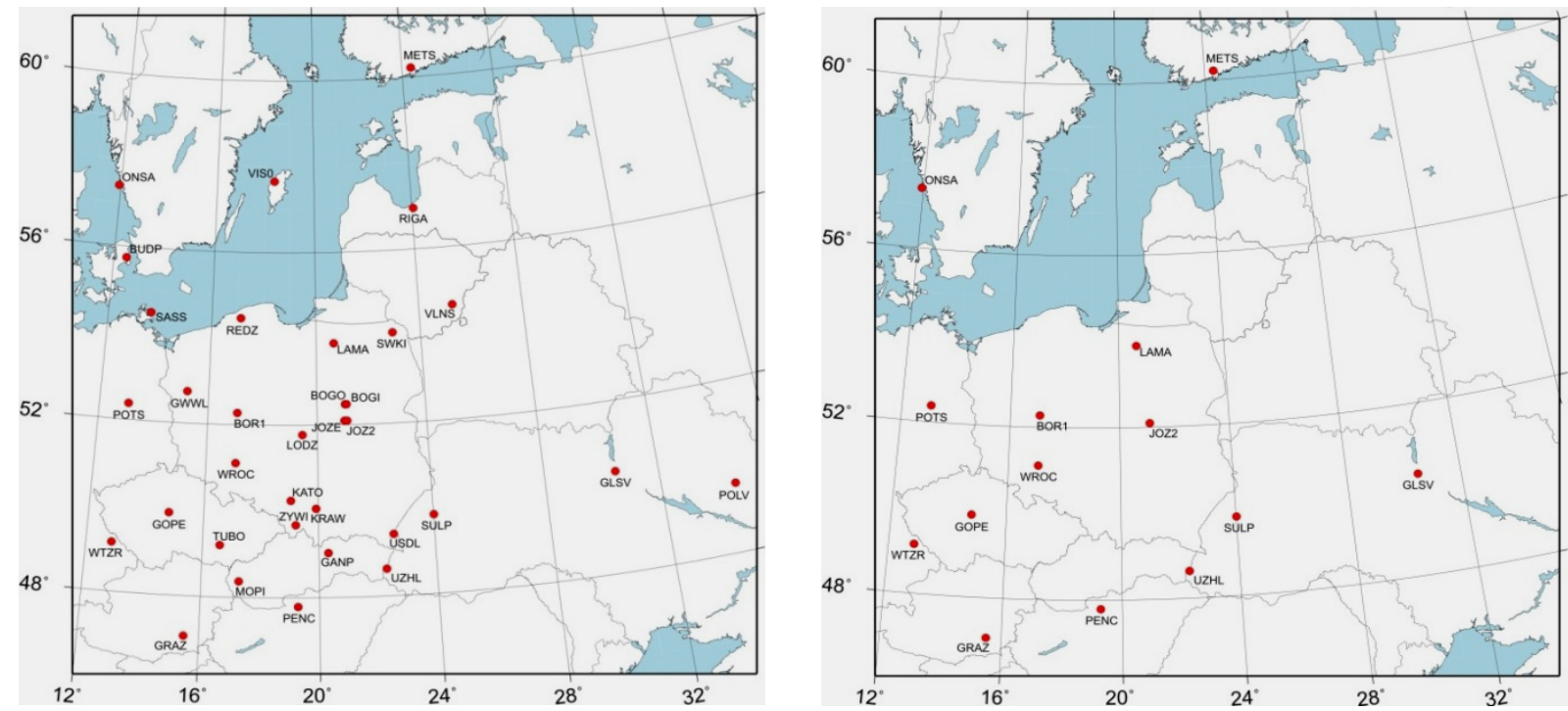

Fig. 1 a, b Reference stations - variant No. 1 (all EPN class A stations which were included during processing, on the left) and variant No. 2 (stations belonging to the IGS only, on the right).
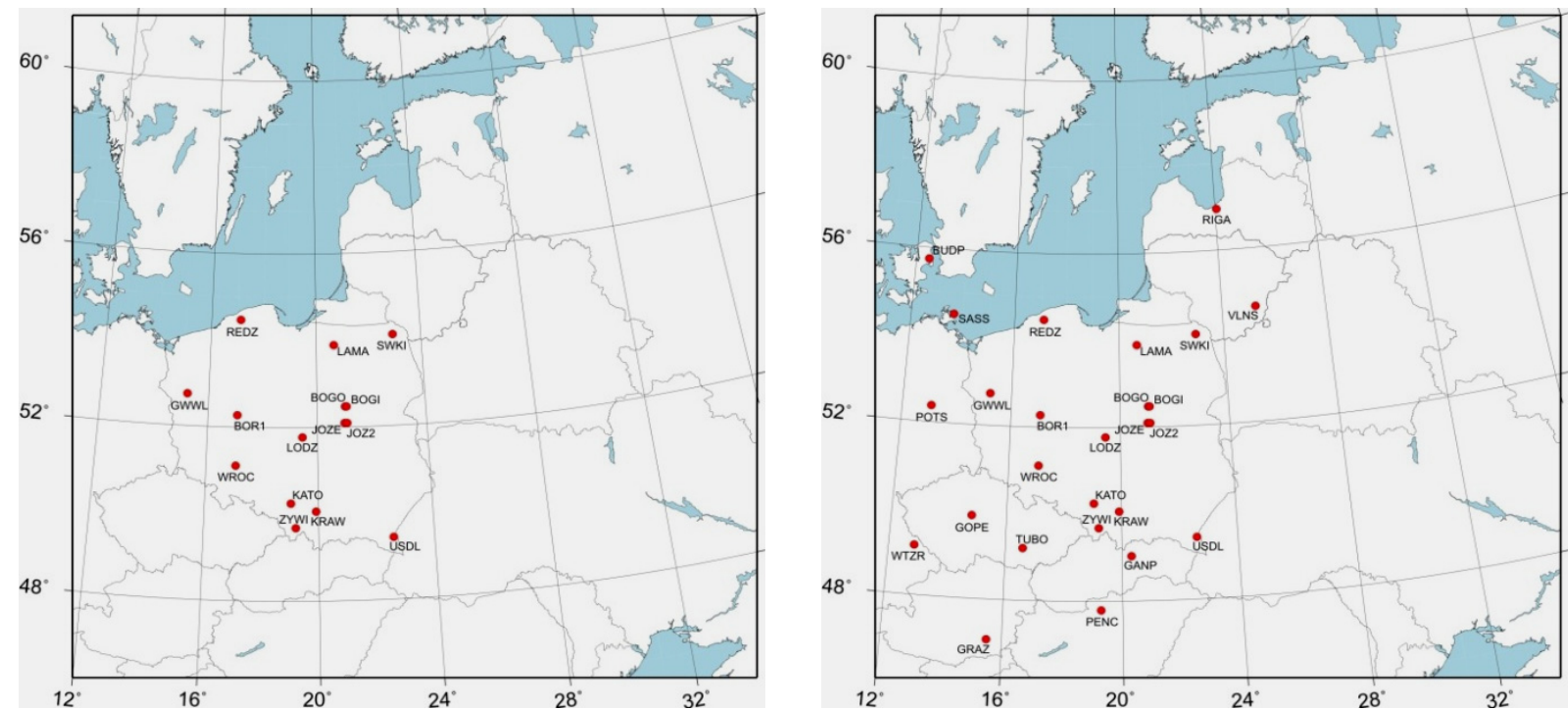

Fig. 2 a, b Reference stations - variant No. 3 (stations located in Poland only, on the left) and variant No. 4 (EPN class A stations with exclusion of stations with noisy time series or significant disturbances, on the right).

same way each time to achieve a different set of coordinates.

\section{RESULTS - ANALYSIS OF COORDINATES}

Coordinates obtained from all variants of reference station distribution were compared with reference values from the EPN solution, which was used as a reference (EPN A ETRF2000 C1600). Figures $4 \mathrm{a}$ and $4 \mathrm{~b}$ illustrate exemplary diagrams of horizontal differences (North, East), and Figure 5a and $5 b$ - the vertical (Up) differences for the coordinates obtained from the calculation using the variants No. 4 and No. 5. Based on analysis of the differences of horizontal coordinates it can be concluded that solutions 1,2 and 4 allowed to obtain consistent results, the solution 3 is slightly inferior to them, and the largest differences (about $1 \mathrm{~cm}$ for some stations) appear in case of solution No. 5. Other solutions with reference stations not evenly distributed also characterize by significant deviations from the catalogue values for some stations (though not as large as in the case of variant No. 5) and low internal consistency. For example, the difference for the component $N$ of RIGA (Riga, Latvia) station for the solution 6 is $+6 \mathrm{~mm}$, and for the solution of 8 is equal to 0 . In the case of vertical coordinates, it turns out that the choice of reference station has a greater impact on the results - individual solutions are less compatible than the horizontal, and the largest relative differences according to the reference values concern 

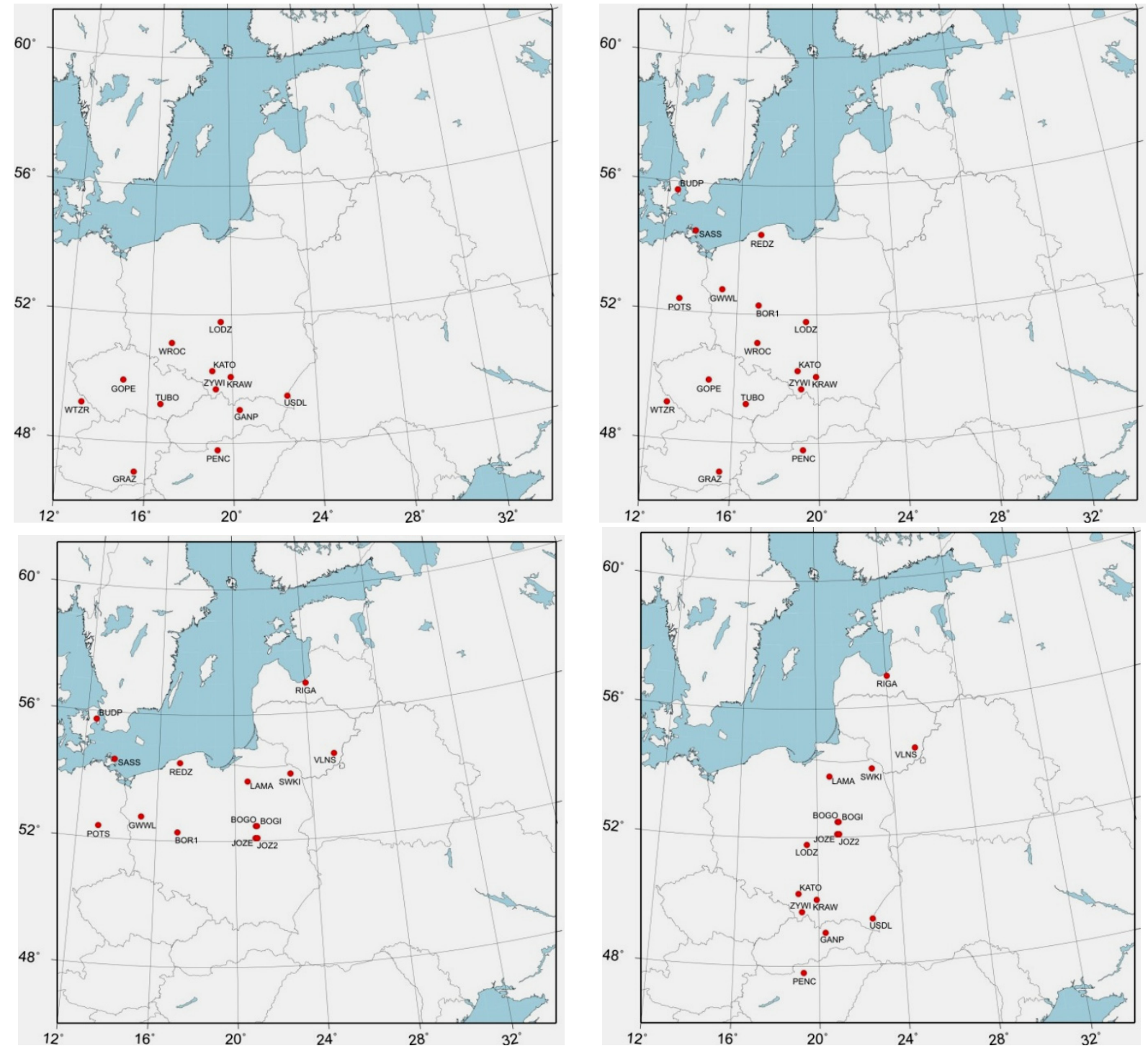

Fig. 3 a, b, c, d Reference stations - variant 5 (southern stations, a), 6 (western stations, b), 7 (northern stations, c) and 8 (eastern stations, $d$ ).
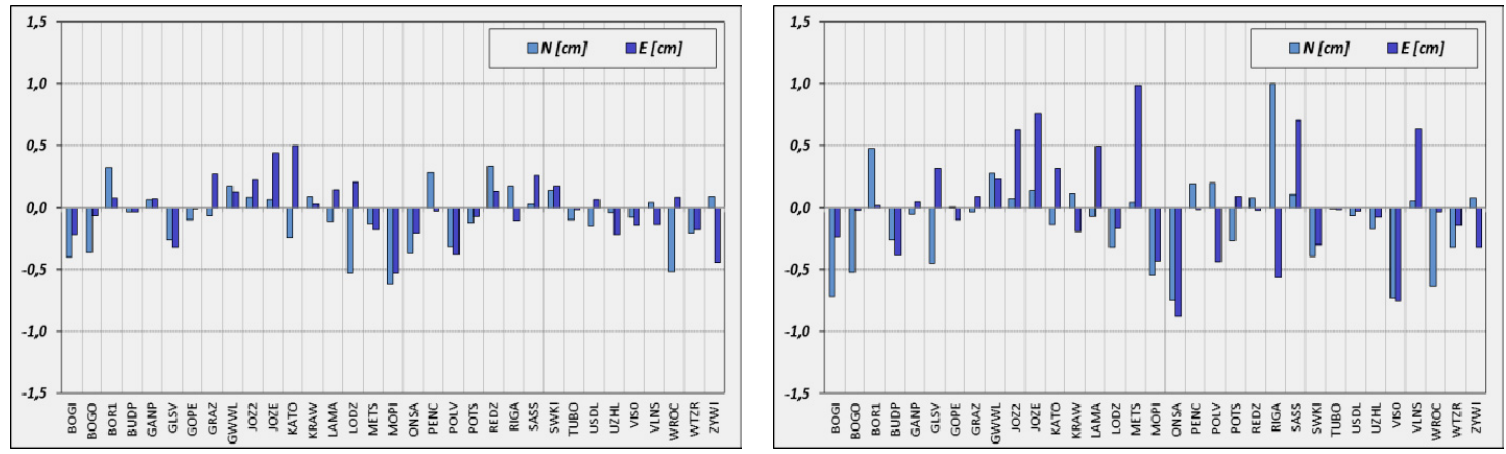

Fig. 4 a, b Differences between horizontal coordinates obtained from processing and their reference values (EPN_A_ETRF2000_C1600) for variant 4 (on the left) and 5 (on the right). 

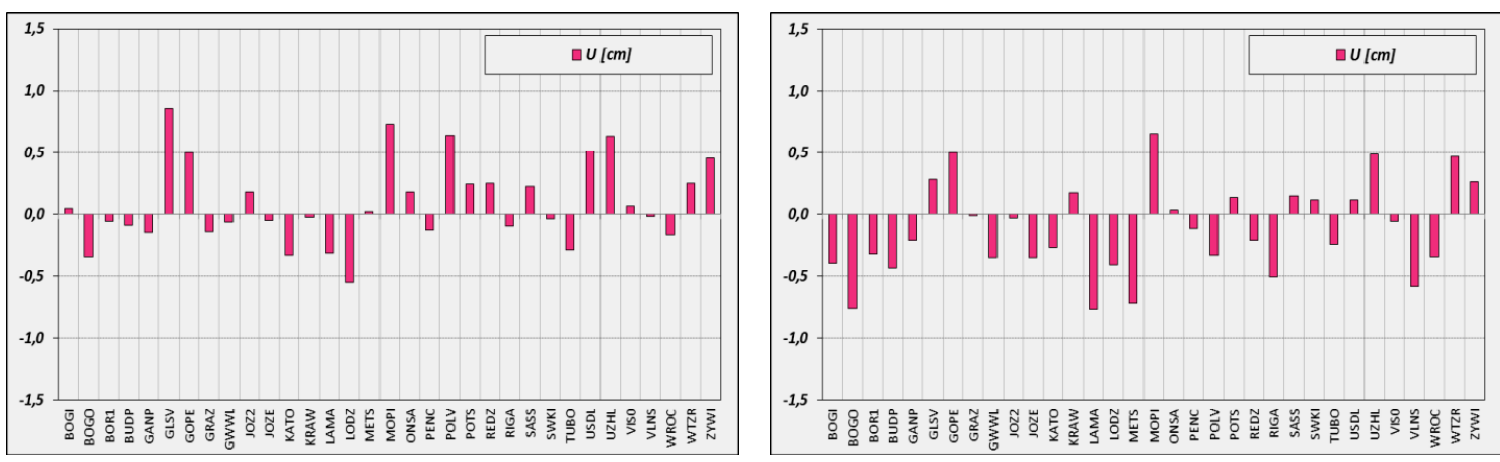

Fig. 5 a, b Differences between vertical coordinates obtained from processing and their reference values (EPN_A_ETRF2000_C1600) for variant 4 (on the left) and 5 (on the right).

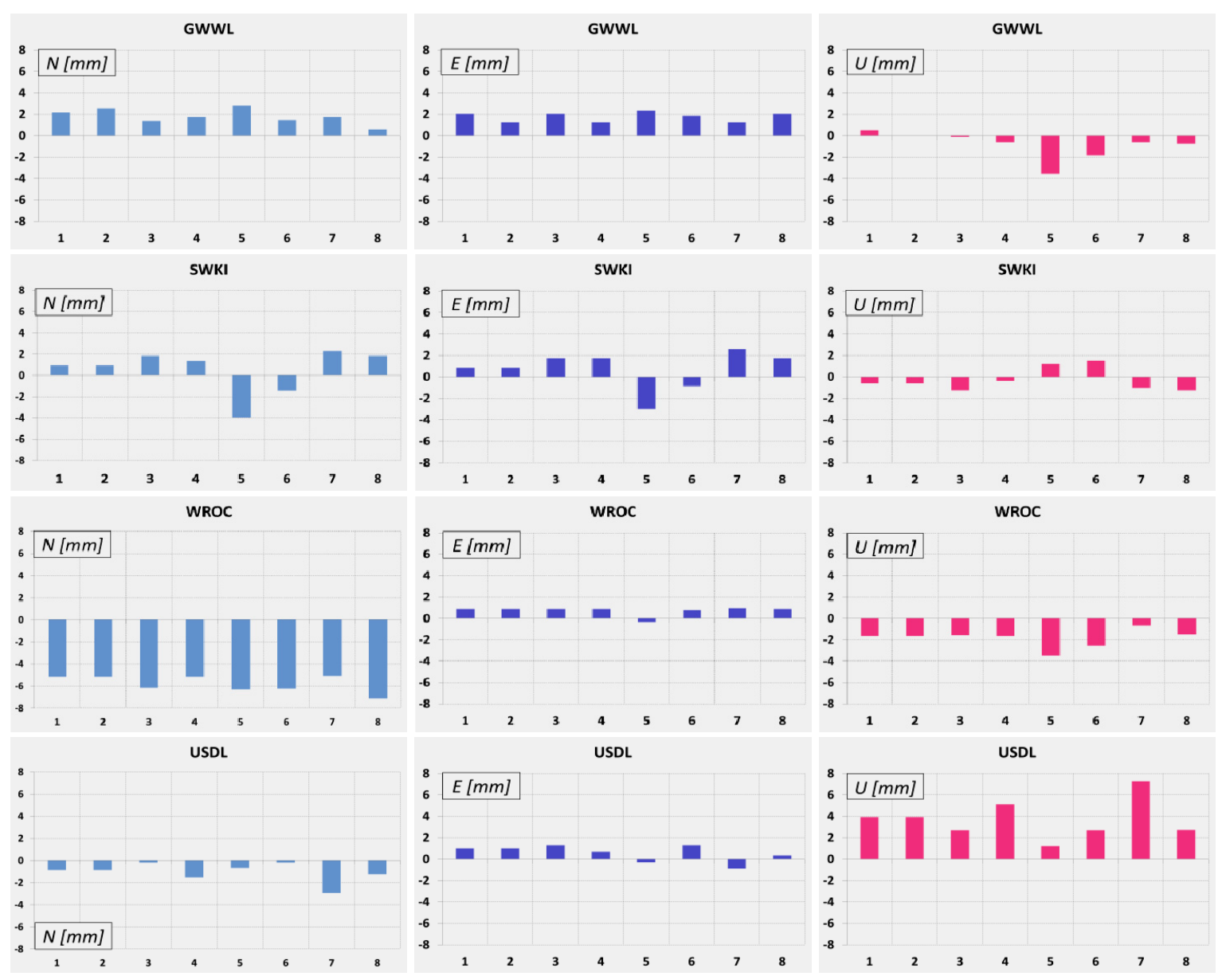

Fig. 6 a-I Differences between $N E U$ compoonents obtained during analysis with different sets of reference stations (variants 1-8) and coordinates reference values (EPN_A_ETRF2000_C1600) for GWWL (a-c) SWKI (d-f), WROC (g-i) and USDL (j-l) stations.

solution 7 - $U$ component differs by more than $1 \mathrm{~cm}$ for GLSV (Kiev, Ukraine), POLV (Poltava, Ukraine) and slightly less than $1 \mathrm{~cm}$ for UZHL (Uzhgorod, Ukraine). So significant differences concern primarily foreign EPN stations placed on the edge of the analysed network.

The differences between the solutions can be better seen in the graphs in Figueres 6 a-1 showing the differences between the $N E U$ components obtained from the processing using different variants of the reference stations and reference values of given stations located in different parts of the country (GWWL (Gorzow Wielkopolski, Poland) - west, SWKI (Suwalki, Poland) - north-east, WROC (Wroclaw, Poland) - south-west and USDL (Ustrzyki Dolne, Poland) - south-east). 

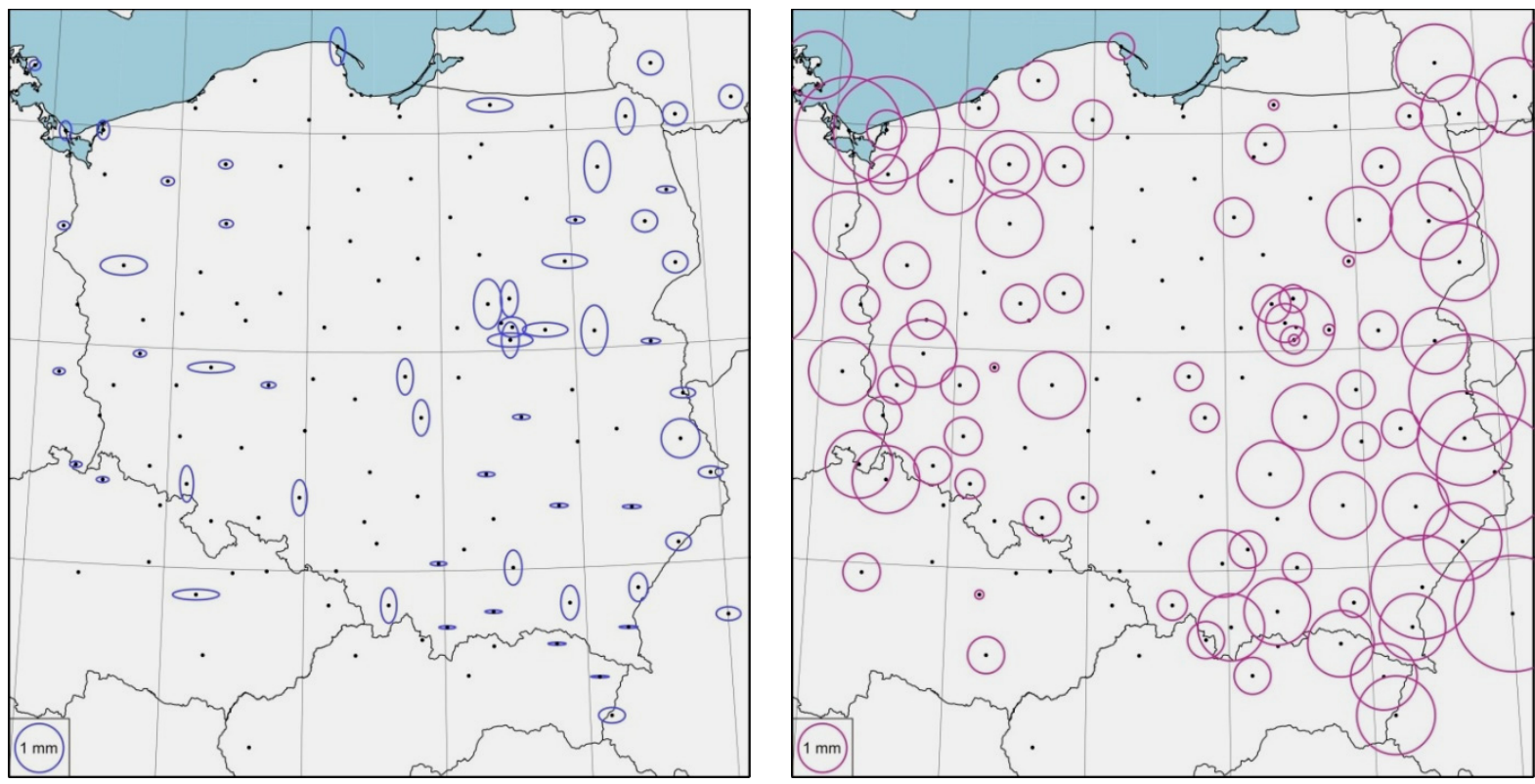

Fig. 7 a, b Differences of horizontal $N-E$ (on the left) and vertical $U$ (on the right) components between solution No. 1 (all EPN class A stations used as reference stations) and solution No. 4 (in which stations with stable time series only were chosen to transfer reference frame).
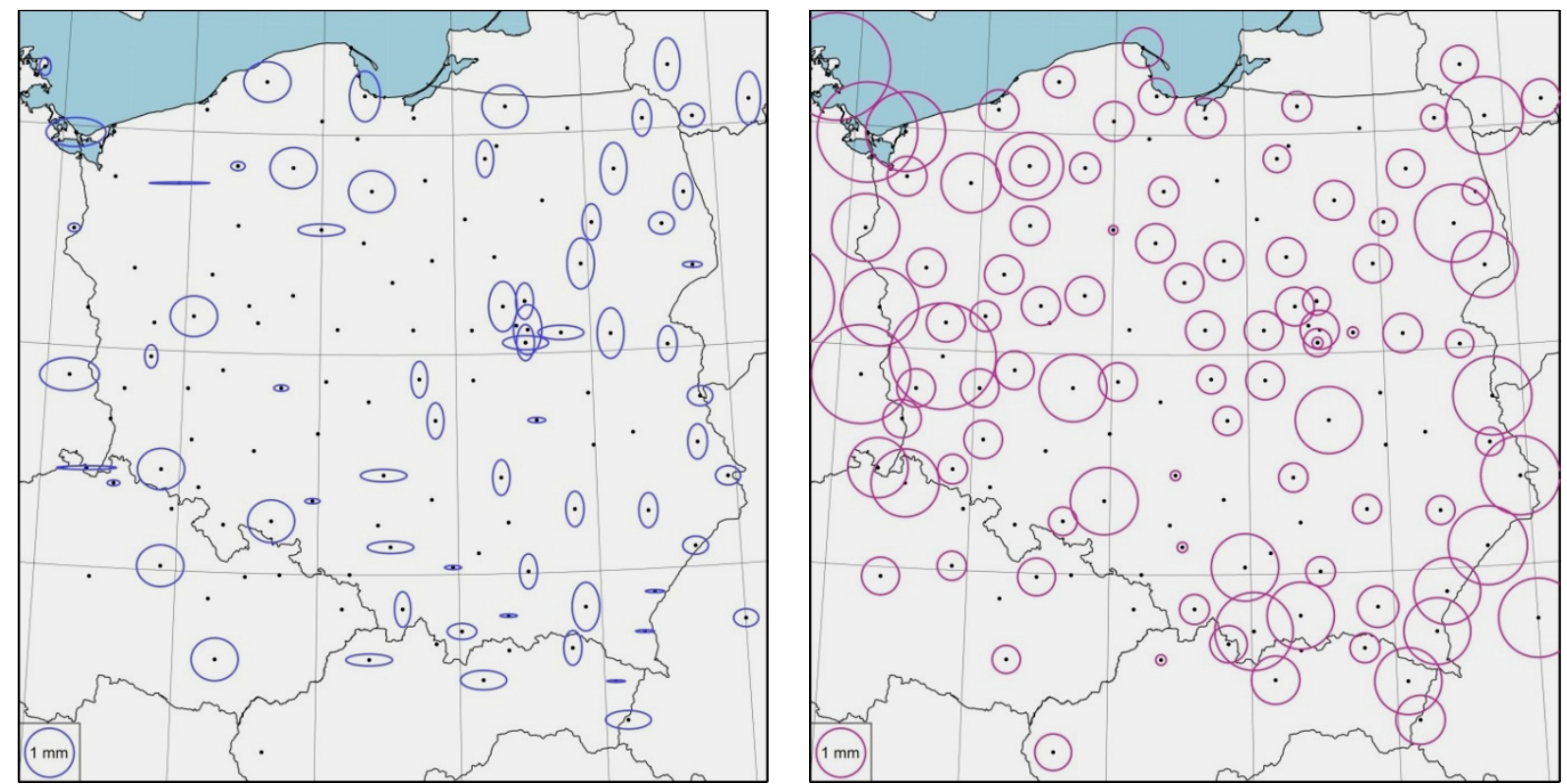

Fig. 8a, b Differences of horizontal $N-E$ (on the left) and vertical $U$ (on the right) components between solution No. 2 (only IGS stations as reference) and solution No. 4.

For all stations inconsistency between the solution No. 5 and the other is widely noticeable. The smallest difference occurs for WROC station located closest to the barycentre of reference stations (this effect is also noticeable in Figure 10). Regardless of the reference station configuration, the component $N$ of station WROC differs by about 5 millimetres from EPN catalogue value, but the largest difference is noticeable for the solution No. 8, in which stations are located in the east. The reference stations selection has not a significant impact on the value of the horizontal component of GWWL station, but the vertical component of the solution No. 5 differs from the other by about 3 millimetres. For SWKI station located farthest from the reference stations barycentre the difference between the solution No. 5 and the other is about 6 millimetres. In the case of SWKI station it also can be seen that significant differences exist also for the solution No. 6, so for the variant in which reference stations are located in the west. For the 

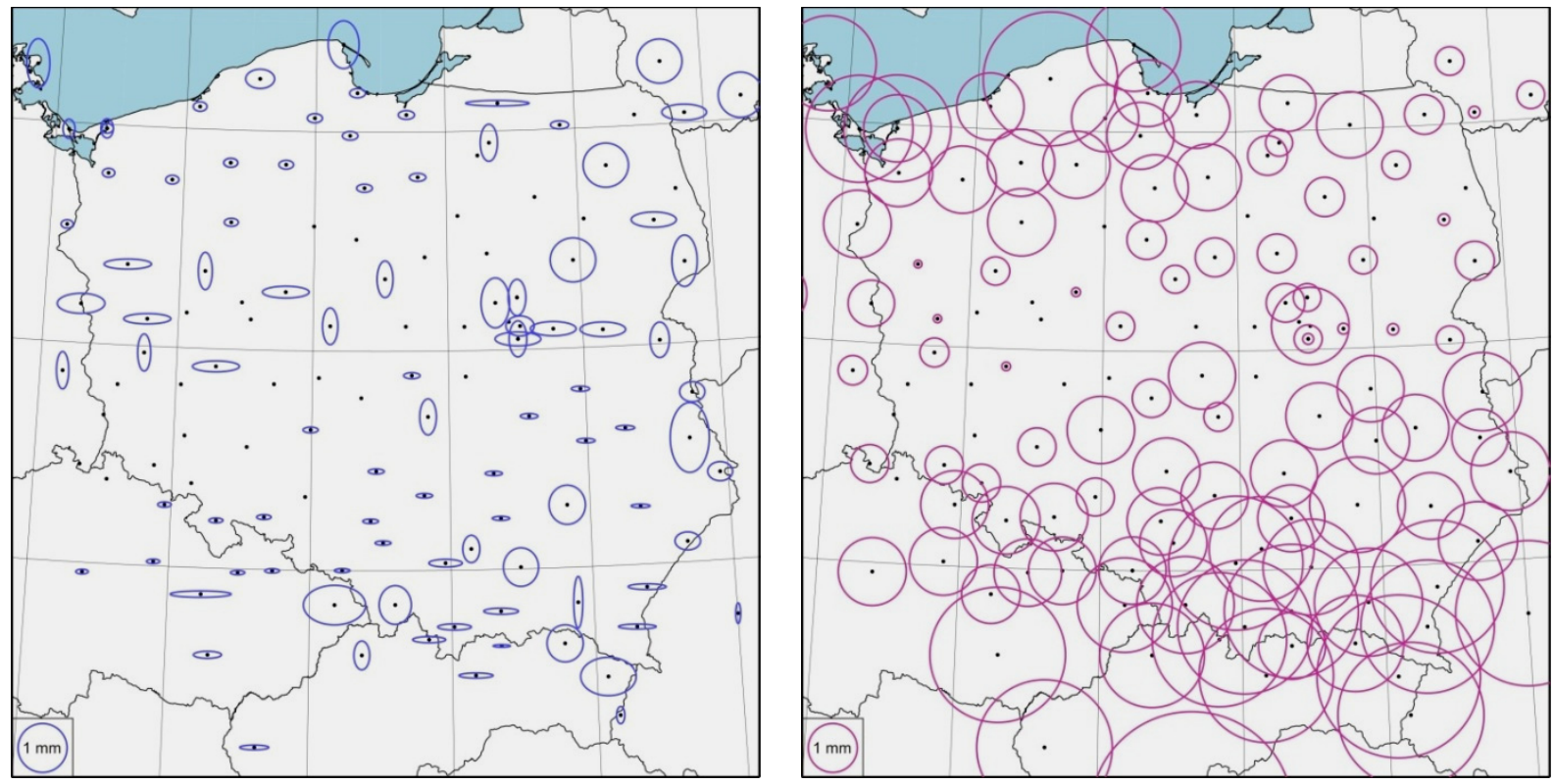

Fig. 9 a, b Differences of horizontal $N-E$ (on the left) and vertical $U$ (on the right) components between solution No. 3 (only Polish stations as reference) and solution No. 4.

southern station USDL largest discrepancies occur for the $N$ and $U$ components of solution No. 7, where stations are located in the north.

In order to assess the reliability of the coordinates of all stations included in the processing as the reference coordinates from solution No. 4 were selected (this solutions is assumed to be the best as it was the closest to recommendations of EUREF). Horizontal and vertical coordinates of all solutions were compared with this solution and presented in graphical form in Figures 7-13.

The solution based on variant No. 1 used as reference stations also the northern METS, VIS0 and ONSA, eastern SULP, POLV and UZHL and located in the south MOPI. Due to the high scatter of the solutions of these stations, they have been rejected from the solution No. 4. The differences are noticeable mainly for the eastern and western stations ASG-EUPOS for the vertical component (Fig. $7 \mathrm{a}, \mathrm{b}$ ).

A similar comparison made for a solution based only on reference stations belonging to IGS network is presented in Figure 8. Significantly lower density of stations transferring the frame resulted in a greater differences (in comparison to the solution No. 1) of horizontal components, but these differences are not significant - only for some stations excessing value of 1 millimetre. More significant differences can be observed for the vertical component: the largest occur for the stations located near the borders of the country (especially along the eastern and western borders) but stations inside the country have been also affected by the lower density of reference stations.

In case of solution No. 3, in which reference stations located on Polish territory were used, the largest differences occur for the vertical component, while the obtained horizontal coordinates do not differ significantly from those of the solutions 1 and 2 (Figs. 9 a, b). Significant differences in height occur mainly for the northern and southern stations. Differences for the foreign stations of ASG-EUPOS reach several millimetres.

The largest differences in the horizontal and vertical coordinates were obtained, as expected, for the solutions using irregularly distributed reference stations. Figures 10-13 show the differences between the coordinates obtained from solutions based on reference stations located sequentially in the south, west, north and east of the analysed network. The largest differences were obtained for the south, which, due to the small number of the eastern stations was in fact a south-western configuration. Shape of differences ellipses in the horizontal components shows that they increase with distance from the reference stations barycentre. The highest values occur for the stations located in the north-east. horizontal coordinates are reaching 1 centimetre and the vertical differences even a few centimetres (Figs. $10 \mathrm{a}, \mathrm{b}$ ).

A similar, though less marked, effect occurs for the coordinates obtained through use the reference stations located in the west (Figs. 11 a, b). Differences of horizontal coordinates of single millimetres concern the north-eastern stations. Significantly higher values of differences occur for the vertical component and reach 1 centimetre for the station from the north-eastern part of Poland and for Lithuanian stations.

In case of using the reference stations located in the north the horizontal coordinates of ASG-EUPOS station change slightly, but the vertical differences of south-eastern stations reach a few millimetres (Fig. 12). Changes in the eastern stations are also 

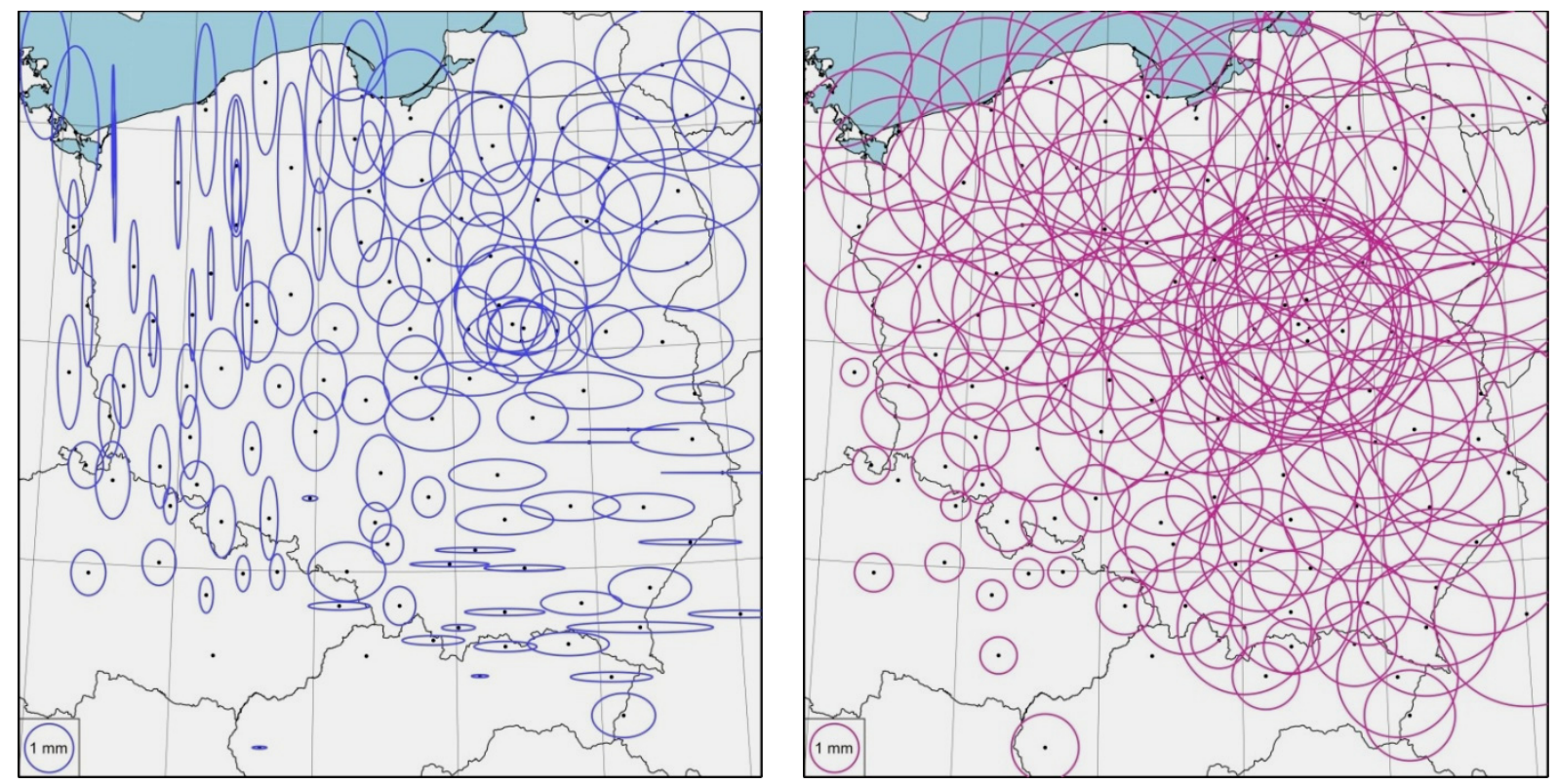

Fig. 10 a, b Differences of horizontal $N-E$ (on the left) and vertical $U$ (on the right) components between solution No. 5 and solution No. 4. Differences of both horizontal and vertical components increase with the distance from the barycentre of reference network.
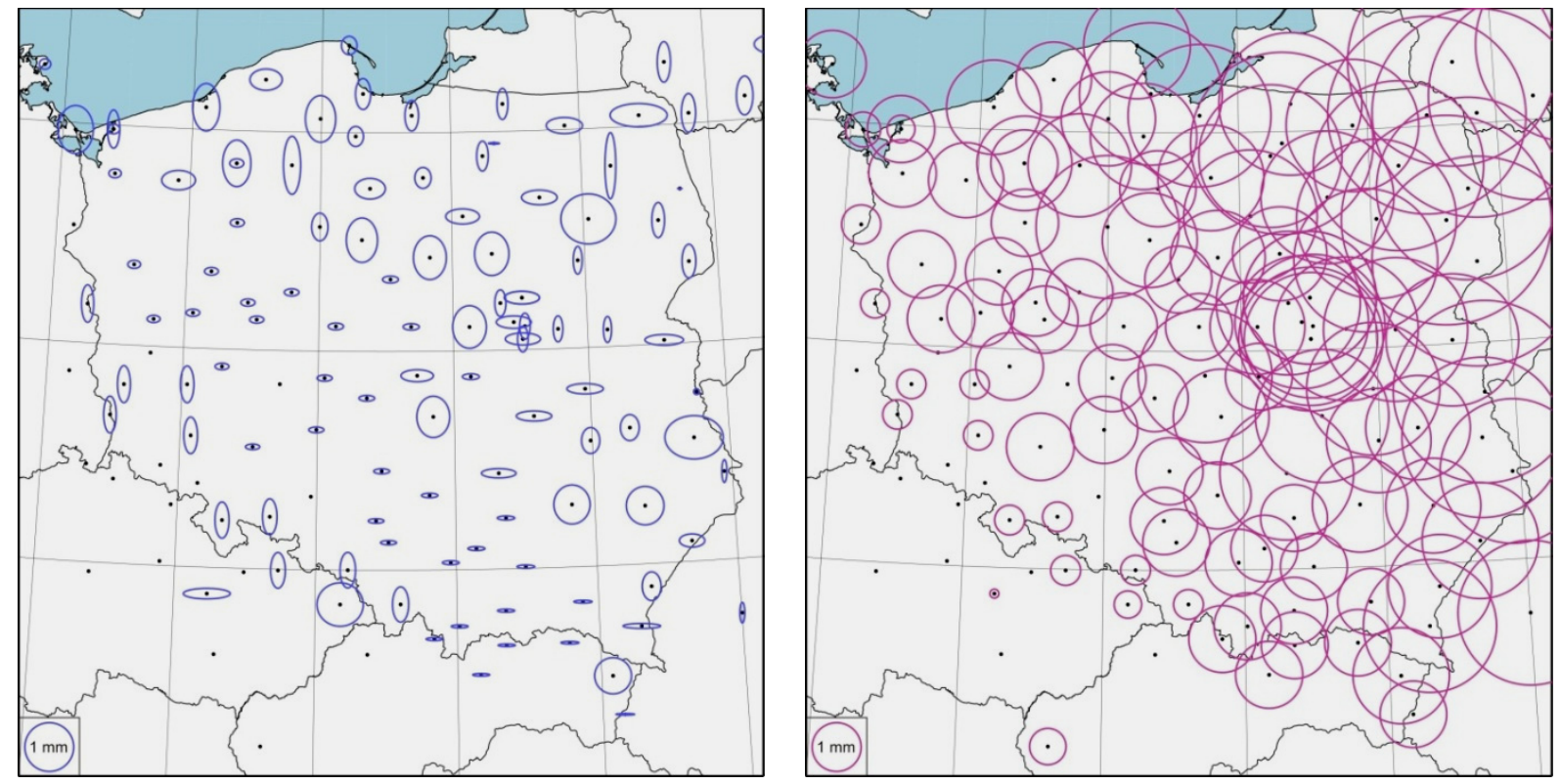

Fig. 11 a, b Differences of horizontal $N-E$ (on the left) and vertical $U$ (on the right) components between solution No. 6 and solution No. 4. Reference stations of solution No. 6 were situated mainly in the west - it is reflected in the values of eastern and north-eastern stations coordinates.

noticeable, which is the result of a small number of reference stations located in the east. The last solution (No. 8) aligned ASG-EUPOS to the EPN through eastern stations. In practice, this meant primarily the use of stations located in the central-eastern part of Poland, and few stations located in the south of the country. It reflects in the size and shape of ellipses representing the horizontal coordinates differences
(Fig. 13b) - differences of a few millimeters are noticeable mainly for the western and southern stations of ASG-EUPOS. The greatest discrepancies for the vertical coordinates were obtained for stations located in the southern and south-western parts of the country and for the Czech and Slovak stations belonging to the ASG-EUPOS. 

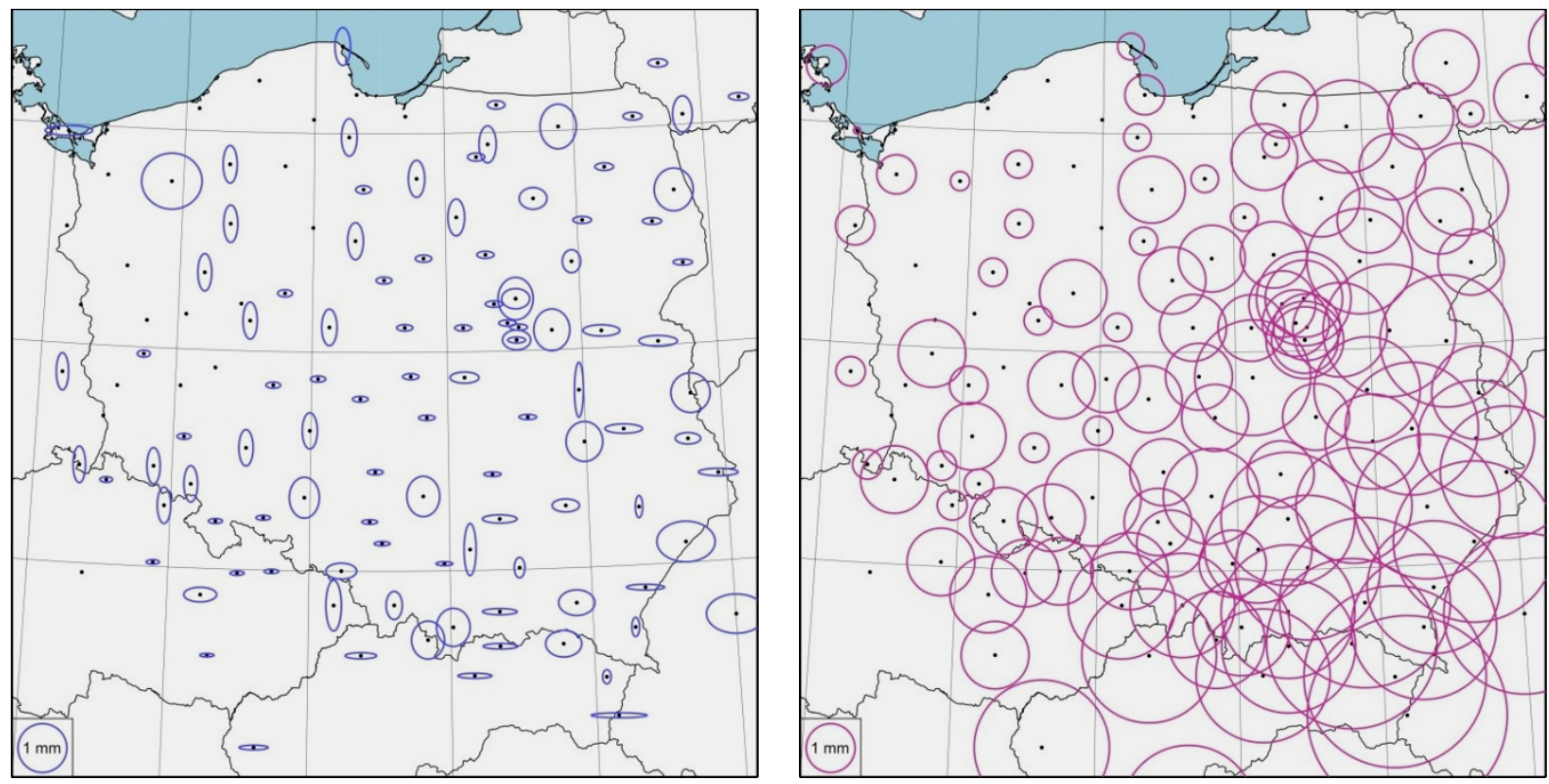

Fig. 12 a, b Differences of horizontal $N-E$ (on the left) and vertical $U$ (on the right) components between solution No. 7 and solution No. 4. Reference stations of solution No. 6 were situated mainly in the north, so the highest discrepancies occur in the south-eastern Poland.
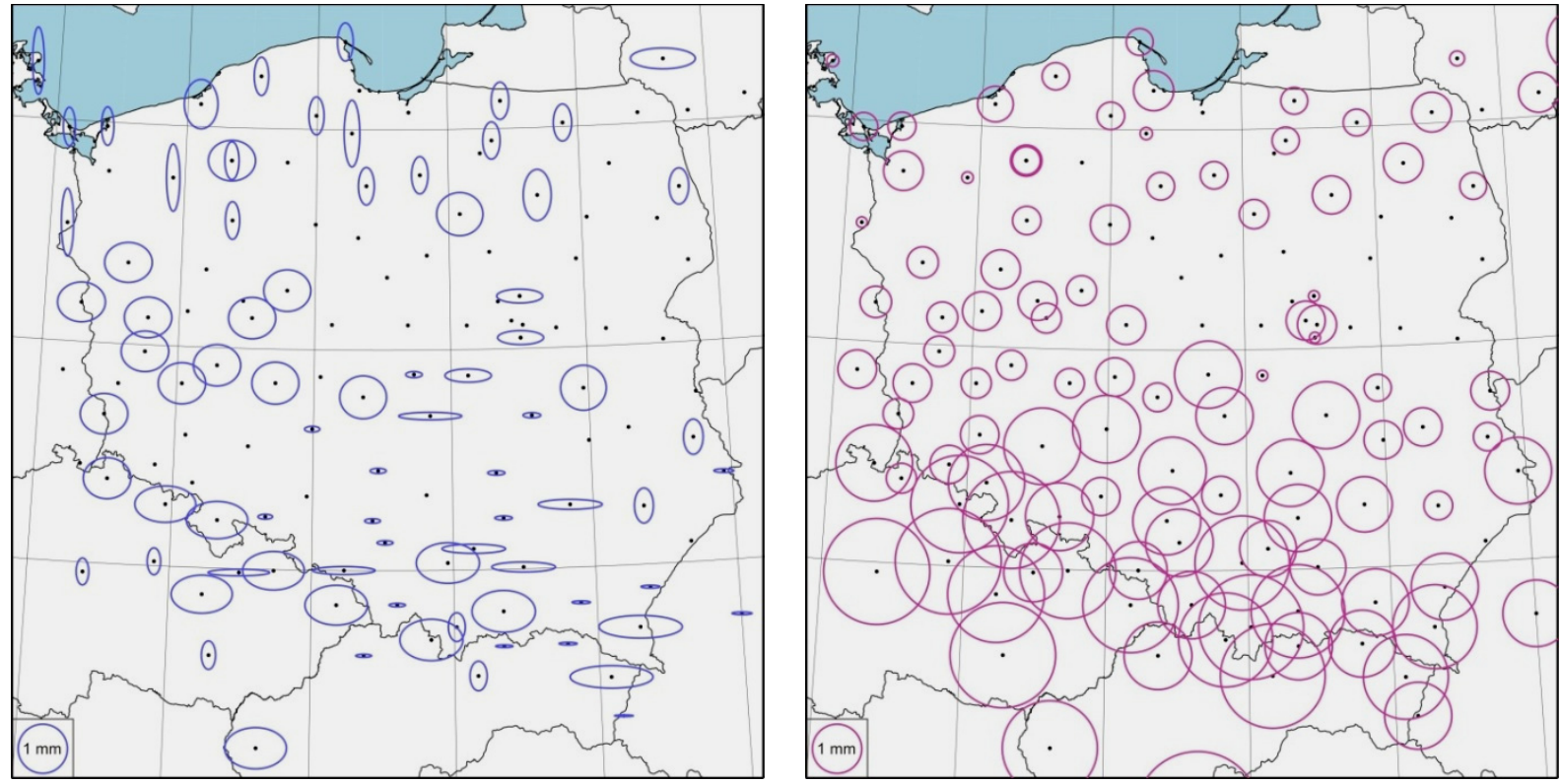

Fig. 13 a, b Differences of horizontal $N-E$ (on the left) and vertical $U$ (on the right) components between solution No. 8 and solution No. 4. Reference stations of solution No. 6 were situated mainly in the central-east Poland, which resulted in very good determination of horizontal and vertical coordinates in this area. The highest discrepancies were obtained for southern-west Poland.

\section{RESULTS - ANALYSIS OF HELMERT PARAMETERS}

Effect of reference stations selection is also visible in the time series of Helmert transformation parameters. The parameters are determined between the cumulative (reference) solution and subsequent weekly solutions using the formula:

$$
X_{1}=X_{2}+T+D X_{2}+R X_{2} \rightarrow X_{1}=X_{2}+A \theta
$$

where $\theta$ is the vector composed of 7 -Helmert transformation parameters, whose values are obtained by the least squares method, $X_{I}$ - reference solution (transformation parameters are determined with respect to this solution, in this case reference solution is the cumulative solution) and $X_{2}$ - epoch solutions (TRF for each week).

Helmert transformation parameters do not have a strict geophysical interpretation, but provide an information about consistency of solutions and their compliance with the cumulative solution (which is a reference for determining the parameters of each 

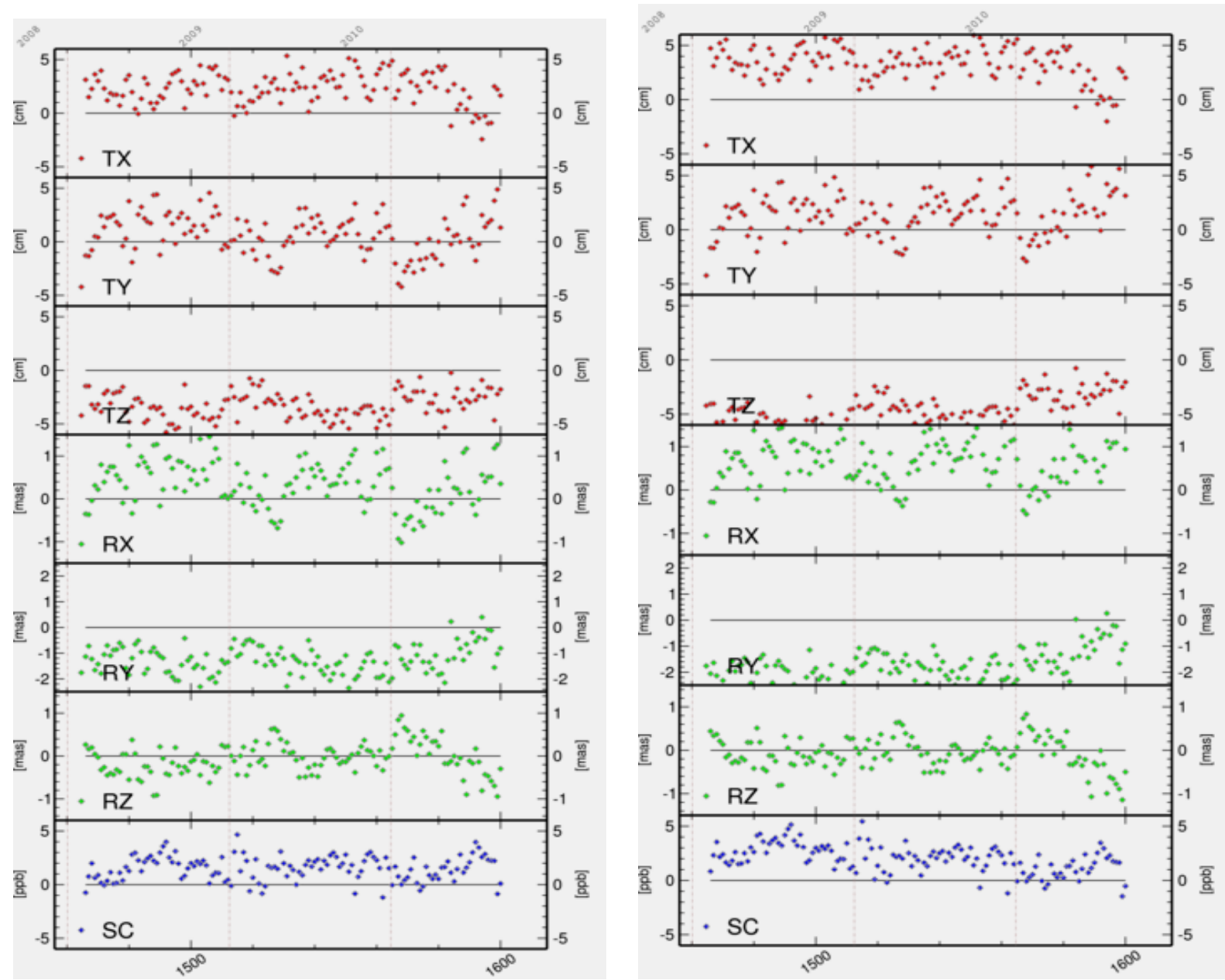

Fig. 14 a, b Time series of Helmert transformation parameters (translation, rotation, scale) for solutions No. 4 (on the left) and No. 5 (on the right).

next solution). In other words, they show fitting of solution in consecutive, weekly TRFs. The average estimated accuracy of determined parameters for ASG-EUPOS case is at the level of 0.4 centimetre for translation components, $0.15 \mathrm{ppb}$ for scale and 0.13 mas for rotation components and it does not change significantly with the reference stations configuration.

Figures $14 \mathrm{a}$ and $14 \mathrm{~b}$ show the graphs of these parameters (translation, rotation and scale) for solutions using variant No. 4 (solution considered the most reliable) and 5 of reference stations (solution with the largest differences regarded as the least reliable).

The absolute values of components of the translation $T_{X}$ and $T_{Z}$ in the solution based on the variant No. 5 are larger (different from zero corresponding to the cumulative solution parameters values) and a linear trend, reflecting worse alignment of determined solution to weekly solutions, can be observed for them. Similarly, time series of rotation and scale components of solution 5 change linearly in time. This means that the solution obtained using worse cumulative configuration of reference station does not correctly reflect the actual position of the station. Worse reference stations configuration influenced the values of $\mathrm{T}_{\mathrm{Y}}$ and $\mathrm{R}_{\mathrm{Z}}$ to a lesser extent.

\section{CONCLUSIONS}

The tests allowed to examine the impact of the reference stations configuration on the reliability of the realization of the ETRS89 in Poland and select the optimal set (the closest to the variant No. 4, but some eastern sites located far from Poland were included; new EPN sites configuration was also taken into consideration), which was used to determine the reference coordinates for monitoring purpose (Szafranek et al., 2013). Analysis were made for the ETRF2000(R05) distribution, because such a frame was available at the time of processing, but the conclusions drawn from the analysis are of general nature and were also used to select the reference stations for expressing coordinates of ASG-EUPOS points in the newest issue of EPN covering GPS weeks 834-1680 which is the regional densification of IGS08 and was published in October 2012 (Kenyeres, 2012). Last implementation, however, does not solve the problem of lack of class A EPN stations located in Eastern Europe. 
By analysing the different solutions it can be concluded that the reliability of solution increases with the number of reference stations. These stations should be evenly distributed throughout the network and beyond. Therefore, the processing of current ASG-EUPOS observations included a larger number of EPN stations (including those located in the east of the continent and located far away from the ASGEUPOS). The choice of reference stations influences to a lesser extent the value of the horizontal coordinates (ignoring the case of extremely uneven distribution of these stations). Greater influence of reference stations configuration can be seen in height component. This is due to the geometry of the network - the stations are located on the mainland and the differences in their horizontal coordinates are much larger than the vertical (vertical component determined by GNSS in general is determined with smaller accuracy than the horizontal components).

In the case of equally distributed reference stations, the results do not differ by more than 1 centimetre for the horizontal component and 2 centimetres for vertical, which is fully satisfactory for the purposes of the realization of the ETRS89 in Poland. In the case of aligning a local networks (national) to the regional frame it is advisable to publish information about reference strategy.

\section{ACKNOWLEDGEMENTS}

The research was partially supported by the grant No. NR09-0010-10/2010 of the National Centre for Research and Development. 1998).

Maps were drawn in GMT (Wessel and Smith,

\section{REFERENCES}

Altamimi, Z.: 2003, Discussion on How to Express a Regional GPS Solution in the ITRF. EUREF 2003 Symposium Proceedings, Verlag des Bundesamts für kartographie und Geodäsie, Frankfurt am Main, 162167.

Altamimi, Z. and Collilieux, X.: 2009, IGS contribution to ITRF. Journal of Geodesy, 83 No. 3-4, 375-383. DOI: $10.1007 / \mathrm{s} 00190-008-0294-\mathrm{x}$

Altamimi, Z., Sillard, P. and Boucher, C.: 2004, CATREF Software: Combination and Analysis of Terrestrial Reference Frames. Publication LAREG SP08, Institut Géographique National.

Altamimi, Z., Collilieux, X. and Métivier, L.: 2011, ITRF2008: an improved solution of the international terrestrial reference frame. Journal of Geodesy, August 2011, 85, Issue 8, 457-473.

Araszkiewicz, A., Bogusz, J., Figurski, M. and Szafranek, K.: 2011, Centre of Applied Geomatics: scientific activities in the frame of EUREF Permanent Network. Reports on Geodesy, No. 2 (91), 75-80.

Boucher, C. and Altamimi, Z.: 2011, Memo: Specifications for reference frame fixing in the analysis of a EUREF GPS campaign (v.8), (http://etrs89.ensg.ign.fr/memoV8.pdf).

Bruyninx, C.: 2004, The EUREF Permanent Network; a multidisciplinary network serving surveyors as well as scientists, GeoInformatics 7, 32-35.
Bruyninx, C., Altamimi, Z., Caporali, A., Kenyeres, A., Lidberg, M., Stangl, G. and Torres, J.A.: 2013, Guidelines for EUREF Densifications v. 5.

Dach, R., Hugentobler, U., Fridez, P. and Meindl, M. (Eds): 2007, Bernese GPS Software Version 5.0. User manual, Astronomical Institute, Universtiy of Bern.

Dow, J.M., Neilan, R. E., and Rizos, C.: 2009, The International GNSS Service in a changing landscape of Global Navigation Satellite Systems, Journal of Geodesy 83, 191-198. DOI: $10.1007 / \mathrm{s} 00190-008-0300-3$

Figurski, M., Szafranek, K., Bogusz, J. and Kamiński, P.: 2010, Investigation on stability of mountainous EUPOS stations' coordinates, Acta Geodyn. Geomater., 7, No. 3 (159), 263-274.

Kenyeres, A., Figurski, M., Legrand, J., Bruyninx, C., Kaminski, P. and Habrich, H.: 2009, Homogeneous reprocessing of the EUREF Permanent Network: First experiences and comparisons, Bulletin of Geodesy and Geomatics No. 3/2009, 207-218.

Kenyeres, A.: 2012, The implementation of IGS08 in the EPN ETRS89 maintance products, (ftp://epncb.oma.be/pub/station/coord/EPN/IGS08_de nsification_V4.pdf).

Legrand, J. and Bruyninx, C.: 2009, EPN Reference Frame Alignment: Consistency of the station positions, Bulletin of Geodesy and Geomatics, LXVIII, No. 1, 19-34.

Legrand, J., Bergeot, N., Bruyninx, C., Wöppelmann, G., Bouin, M.N. and Altamimi, Z.: 2010, Impact of regional reference frame definition on geodynamic interpretations, Journal of Geodynamics, 49, No. 3-4, 116-122. DOI: 10.1016/j.jog.2009.10.002.

Legrand J., Bruyninx C. and Bergeot N.: 2011, Results and comparisons of a local and a regional reprocessed GNSS network, Bulletin of Geodesy and Geomatics 69 No. 2-3, 257-267.

Penna, N.T. and Stewart, M.P.: 2003, Aliased tidal signatures in continuous GPS height time series, Geophysical Research Letters, 30, No. 23. DOI: $10.1029 / 2003$ GL018828

Rebischung P., Griffiths, J., Ray, J., Schmid, R., Collilieux, X. and Garayt, B.: 2012, IGS08: the IGS realization of ITRF2008. GPS Solutions, 16, No.4, 483-494. DOI: 10.1007/s10291-011-0248-2

Szafranek, K., Bogusz, J. and Figurski, M.: 2013, GNSS reference solution for permanent station stability monitoring and geodynamical investigations: the ASG-EUPOS case study, Acta Geodyn. Geomater., 10, No. 1 (169), 67-75.

Shagimuratov, I.I., Baran, L.W., Wielgosz, P. and Yakimova, G.A.: 2002, The structure of mid- and high-latitude ionosphere during September 1999 storm event obtained from GPS observations, Annales Geophysicae, 20, No. 5, 665-660.

Wessel, P. and Smith, W.H.F.: 1998, New, improved version of the Generic Mapping Tools. Released, EOS Trans. AGU, 79, 579.

Wöppelmann, G., Bouin, M.-N. and Altamimi, Z.: 2008, Terrestrial reference frame implementation in global GPS analysis at TIGA ULR consortium, Physics and Chemistry of the Earth, 3-4, No. 33, 217-224. DOI: $10.1016 /$ j.pce.2006.11.001 